\title{
QUALIDADE MICROBIOLÓGICA DE SALAMES E QUEIJOS COLONIAIS PRODUZIDOS E COMERCIALIZADOS NA REGIÃO SUDOESTE DO PARANÁ
}

\author{
Kérley Braga Pereira Bento Casaril ${ }^{1}$, Cláudia Braga Pereira Bento², Katiana Henning ${ }^{3}$, Maristela Pereira ${ }^{4}$, \\ Valmira Antunes Dias ${ }^{4}$
}

\begin{abstract}
RESUMO - Produtos coloniais como salames e queijos são amplamente consumidos na região sul do Brasil. Com o objetivo de avaliar a qualidade higiênico-sanitária de salames e queijos coloniais produzidos de forma artesanal e comercializados na região Sudoeste do Paraná, doze amostras de salame tipo colonial e dez amostras de queijo tipo colonial foram submetidas às seguintes análises microbiológicas: contagem de coliformes totais, contagem de coliformes termotolerantes, confirmação da Escherichia coli, contagem de mesófilos aeróbios estritos e facultativos, pesquisa de Salmonella spp. e contagem de estafilococos coagulase positiva. Das amostras de salame analisadas, 33,33 \% apresentaram contagens de coliformes totais maiores que $1100 \mathrm{NMP} / \mathrm{g}$ e 16,66\% não atendem à legislação vigente quanto à presença de coliformes termotolerantes e apresentaram positividade para $E$. coli . A contagem de mesófilos aeróbios variou de 8,7 x $10^{5}$ a 2,43 x $10^{8} \mathrm{UFC} / \mathrm{g}$. Além disso, 50\% das amostras estavam contaminadas com Staphylococcus spp. e uma apresentou positividade no teste de coagulase. Das amostras de queijos $70 \%$ apresentaram contagens de coliformes totais maiores que 1100 NMP/g e 50\% não atendem à legislação vigente quanto à presença de coliformes termotolerantes. Além disso, quatro amostras estavam contaminadas com E. coli e uma amostra com Salmonella spp. tornando-os queijos impróprios para o consumo. Os resultados obtidos indicam que os salames e os queijos coloniais produzidos e comercializados na região sudoeste do Paraná devem merecer atenção dos órgãos de saúde pública, pois representam um risco potencial para a saúde do consumidor.
\end{abstract}

Palavras chave: legislação vigente, qualidade microbiológica, queijo, salame.

\section{MICROBIOLOGICAL QUALITY OF SALAMI AND CHEESES COLONIAL PRODUCED AND MARKETED IN THE SOUTHWEST OF PARANÁ}

\begin{abstract}
Colonial products such as salami and cheeses are widely consumed in the south region of Brazil. With the objective of evaluating the sanitary-hygienic quality of salami and cheeses colonial produced by hand and marketed in the southwest region of Paraná, twelve samples of salami colonial type and ten samples of colonial type cheese samples were submitted to the following microbiological analysis: count of total coliforms, count of thermotolerant coliforms, confirmation of Escherichia coli, counts of mesophilic aerobes strict and facultatives, survey of Salmonella spp. And count of staphylococci coagulase positive. Of samples of salami analyzed $33.33 \%$ had total coliforms greater than $1100 \mathrm{MPN} / \mathrm{g}$. The counts of aerobic mesophilic ranging from $8.7 \times 10^{5}$ to $2.43 \times 10^{8} \mathrm{CFU} / \mathrm{g}$. Furthermore, $50 \%$ of the samples were contaminated with Staphylococcus spp. and presented positivity in the coagulase test. Of cheese samples analyzed $70 \%$ were total coliforms greater than $1100 \mathrm{MPN} / \mathrm{g}$ and 50\% does not meet the current legislation regarding the presence of thermotolerant coliforms. In addition, four samples are contaminated with E. coli and one samples with Salmonella spp. becoming cheeses unfit for consumption. The results obtained indicate that the salami and the colonial cheese produced and marketed in the Southwest region of Paraná should receive attention from public health organs, since they represent a potential risk to consumer health.
\end{abstract}

Keywords: cheese, current legislation, microbiological quality, salami.

\footnotetext{
${ }^{1}$ Doutora em Ciência de Alimentos. Profa da Universidade Estadual do Oeste do Paraná, Francisco Beltrão, Paraná (email:kcasaril@gmail.com).

${ }^{2}$ Pós-doutora em Microbiologia Agrícola. Prof ${ }^{a}$. da Universidade Federal dos Vales do Jequitinhonha e Mucuri, Unaí, Minas Gerais.

${ }^{3}$ Mestranda em Ciências da Saúde. Universidade Estadual do Oeste do Paraná, Francisco Beltrão, Paraná.

${ }^{4}$ Economista Doméstico. Universidade Estadual do Oeste do Paraná, Francisco Beltrão, Paraná.
} 


\section{INTRODUÇÃO}

O consumo de produtos artesanais/coloniais por ser considerado, pela população, mais natural e saboroso é uma tradição na região sul do Brasil, em especial, no sudoeste paranaense. Nesta região, a produção artesanal/colonial de derivados de leite e da carne suína é expressiva, sendo realizada por cerca de 60 agroindústrias familiares. A produção em pequena escala gira em torno de 0,5 a 4 toneladas mensais, sendo que $81 \%$ da produção são comercializadas no mercado local e regional. É caracterizada por pequenas unidades no meio rural, realizada de acordo com tradições familiares e geralmente com baixo padrão tecnológico, permitindo mudanças em relação à sua composição (Holowka et al., 1999; Marchi, 2007).

Dentre os produtos artesanais mais apreciados estão os salames e os queijos coloniais. Em se tratando de embutidos coloniais, os salames são produtos de grande aceitação na região sul do Brasil associado a fatores como, preço, conveniência de compra e, principalmente, pela influência das culturas alemã e italiana (Ritter et al., 2003; Magro \& Klein, 2006).

Segundo a Instrução Normativa $\mathrm{n}^{\circ} 22$, de 31 de julho de 2000 "Salame é conceituado como produto cárneo industrializado obtido de carne suína ou suína e bovina adicionado de toucinho, ingredientes, embutido em envoltórios naturais e/ou artificiais, curtido, fermentado, maturado, defumado ou não e dessecado". O processo tecnológico que define os embutidos fermentados compreende a moagem da carne in natura (em granulometria variável conforme o tipo de produto), a mistura com gordura, sal, agentes de cura e temperos, o embutimento em tripas, a maturação e a desidratação (Brasil, 2000).

Os salames coloniais são elaborados com carnes cruas que não passam por cocção ao longo do processamento e antes de seu consumo. Segundo Oliveira \& Mendonça(2004) a segurança microbiológica desses produtos resulta da associação de obstáculos, como baixa atividade de água, adição de nitrito e cloreto de sódio, baixo pH e presença de substâncias antimicrobianas formadas durante o processamento, bem como de excelentes condições higiênicas no seu processamento tecnológico. A combinação dos obstáculos presentes nos produtos cárneos fermentados é suficiente para impedir o desenvolvimento de bactérias deteriorantes e da maioria dos patógenos.
No entanto, em alguns estudos têm relatado a ocorrência de micro-organismos patogênicos e deterioradores, dentre os quais pode-se destacar Escherichia coli, Salmonella spp. e Listeria spp. em produtos fermentados mesmo em condições desfavoráveis (Työppönen, Petäjä \& Mattila-Sandholm, 2003; Lindqvist \& Lindblab, 2009; Gottardo et al., 2011).

O queijo colonial destaca-se como um dos queijos mais consumidos e aceitos na região sudoeste do Paraná. Apresenta fabricação simples e valor nutritivo indiscutível. Porém, seu processamento, na maioria dos casos, ainda é artesanal e apresenta deficiências tecnológicas durante as fases de fabricação, armazenamento e distribuição. Embora, na maioria das vezes a produção e a comercialização destes queijos sejam consideradas clandestinas, estas práticas são frequentes e não podem ser ignoradas. A sua proibição pode acarretar, em determinadas regiões do país, um problema social, para as populações que sobrevivem dessa atividade (Ide \& Benedet, 2001; Fariña et al., 2008) considerando que, o queijo colonial tem importância na vida econômica da população que reside no meio rural, e que tem nessa atividade uma fonte alternativa de renda (Ide \& Benedet, 2001). A preocupação principal diz respeito às condições higiênico-sanitárias no processamento do queijo, visto que a contaminação microbiana é a maior causa de perdas de qualidade dos produtos e de infecções e intoxicações alimentares (Freo \& Reolon, 2006). Dentre os produtos derivados do leite, o queijo é considerado um veículo frequente de patógenos de origem alimentar e, em especial, os queijos artesanais por serem, na maioria das vezes, elaborados a partir de leite cru e não sofrerem processo de maturação. Assim, "a contaminação microbiana desses produtos assume destacada relevância tanto para a indústria, pelas perdas econômicas, como para a saúde pública, pelo risco de causar doenças transmitidas por alimentos" (Feitosa et al., 2003).

Em vários estudos sobre avaliação da qualidade microbiológica de queijos produzidos com leite cru relatam-se a ocorrência de micro-organismos patogênicos e contagem de micro-organismos deterioradores em números que excedem, às vezes, os limites estabelecidos pela legislação (Brasil, 2001). Dentre as bactérias patogênicas, em geral, destacam-se Salmonella spp., Escherichia coli e Staphylococcus aureus (Feitosa et al., 2003; Kottwitz \& Guimarães, 2003; Cavalcante et al., 2007). 
Tradicionalmente, produzidos de maneira artesanal no próprio domicílio ou em pequenas indústrias, salames e queijos coloniais são comercializados em feiras, supermercados e em bancas de produtos coloniais localizadas ao longo de rodovias. A fim de garantir proteção à saúde da população, a Agência Nacional de Vigilância Sanitária publicou no Diário Oficial da União (DOU), a Resolução RDC n 12 , de 02 de janeiro de 2001 que estabelece os padrões microbiológicos para alimentos. Para o salame, o máximo tolerado de coliformes termotolerantes/g é de $10^{3} \mathrm{UFC}$, Estafilococos coagulase positiva/g $5 \times 10^{3}$ UFC e ausência de Salmonella spp. em $25 \mathrm{~g}$ de amostra. Já para o queijo de média umidade o máximo tolerado de coliformes termotolerantes/g é de $10^{3} \mathrm{UFC}$, Estafilococos coagulase positiva/g $10^{3}$ UFC e ausência de Salmonella spp. e L. monocytogenes em $25 \mathrm{~g}$ de amostra (Brasil, 2001).

Por serem produtos amplamente produzidos e consumidos objetivou-se avaliar a qualidade microbiológica de salames e queijos coloniais produzidos e comercializados no sudoeste paranaense.

\section{MATERIAL E MÉTODOS}

Foram avaliadas 12 amostras de salame tipo colonial e dez amostras de queijo tipo colonial produzidos e comercializados na região Sudoeste do Paraná, adquiridas em supermercados, feiras livres e propriedade rurais de produtores, entre julho a setembro de 2014. As amostras foram coletadas em diversos pontos de vendas de Francisco Beltrão e levou em consideração os diferentes produtores.

Dentre as 12 amostras de salame, sete eram inspecionadas pelo Serviço de Inspeção Municipal (S.I.M.), quatro pelo Serviço de Inspeção Estadual (S.I.P.) e uma amostra era de fabricação artesanal (sem inspeção). Dentre as dez amostras de queijo três eram inspecionadas pelo S.I.M., três pelo S.I.P. e quatro amostras eram de fabricação artesanal (sem inspeção).

As amostras de queijos inspecionadas eram vendidas refrigeradas, embaladas individualmente em sistema a vácuo e em embalagens rotuladas. As amostras de queijo sem registros eram vendidas em sacos plásticos comuns, desprovidas do sistema a vácuo. Todas as amostras foram adquiridas dentro do prazo de validade estipulado nas embalagens pelo fabricante ou pelo local que embalou os alimentos. $\mathrm{O}$ transporte foi realizado após as amostras serem acondicionadas em recipiente de isopor com gelo, sendo imediatamente encaminhadas ao Laboratório de Biologia da Universidade Estadual do Oeste do Paraná e submetidas às seguintes análises microbiológicas: contagem de coliformes totais, coliformes termotolerantes e Escherichia coli, contagem de mesófilos aeróbios totais, pesquisa de Salmonella sp., contagem de Staphyloccocus sp. e pesquisa de estafilococos coagulase positiva. Todas as análises foram realizadas segundo a metodologia descritas por Silva et al. (2010).

\section{Preparo das amostras para análise microbiológica}

Alíquotas de $25 \mathrm{~g}$ de cada amostra foram pesadas, assepticamente, e homogeneizadas manualmente durante um minuto com $225 \mathrm{~mL}$ de água peptonada tamponada $0,1 \%$ (Himedia, Mumbai, Índia), correspondendo à diluição $10^{-1}$. Diluições decimais, a partir da diluição $10^{-1}$, foram preparadas em tubos que continham $9 \mathrm{~mL}$ de água peptonada até a diluição $10^{-5}$.

\section{Contagem de coliformes totais}

A pesquisa de coliformes totais foi feita utilizandose o método do Número Mais Provável (NMP), pela técnica dos tubos múltiplos, com utilização de três séries de três tubos contendo Caldo Lauril Sulfato Triptose - CLST (Himedia Mumbai, Índia) e tubos de Durhan invertidos. Os tubos foram inoculados, transferindo-se $1 \mathrm{~mL}$ das diluições $10^{-3}$ a $10^{-5}$ para cada uma das séries, seguidos de incubação em estufa bacteriológica a $35^{\circ} \mathrm{C}$, durante 48 horas e observouse a produção ou não de gás.

Dos tubos de Durham, presuntivamente positivos, com turvação e produção de gás transferiu-se, com auxílio de uma alça de platina, uma alçada para tubos contendo Caldo Verde Brilhante Bile 2\% (Himedia Mumbai, Índia) nas mesmas condições de tempo e temperatura. O NMP de coliformes totais por grama de alimento foi determinado com base na tabela utilizada para o cálculo dos coliformes totais.

\section{Contagem de coliformes termotolerantes}

A partir dos tubos positivos, com produção de gás do CLST, transferiu-se com auxílio de alça de platina, uma alçada para tubos contendo Caldo EC (Escherichia coli), seguido de incubação em banho-maria, $44,5^{\circ} \mathrm{C}$, por 24 a 48 horas e observou-se a produção de gás. O NMP de coliformes termotolerantes por grama de 
alimento foi determinado com base na tabela utilizada para o cálculo dos coliformes.

\section{Confirmação da Escherichia coli}

De cada tubo positivo no caldo EC, estriou-se uma alçada da cultura em Ágar Eosina Azul de Metileno (EMB) (Himedia) e incubou-se a $35^{\circ} \mathrm{C}$, por 24 horas. Após, observou-se o crescimento de colônias típicas de $E$. coli. A partir das colônias típicas de $E$. coli foram realizadas as seguintes provas bioquímicas: Prova Agar Tríplice Açúcar Ferro (TSI), Prova do Citrato de Simmons, Prova do Vermelho de Metila (VM), Prova do VogesProskauer (VP), Prova de descarboxilação da Lisina, Prova de $\mathrm{H}_{2} \mathrm{~S}$, indol e motilidade (Koneman et al., 2006).

\section{Contagem de mesófilos aeróbios estritos e facultativos}

Alíquotas de $1 \mathrm{~mL}$ das diluições $10^{-3}$ a $10^{-5}$ preparadas conforme "Preparo das Amostras para Análise Microbiológica" foram transferidas para placas devidamente esterilizadas. Após, foi adicionado um volume de $20 \mathrm{~mL}$ de Agar Padrão para Contagem (PCA) (Himedia) a $45^{\circ} \mathrm{C}$. Depois da homogeneização, as placas foram incubadas invertidas em estufa bacteriológica a $35^{\circ} \mathrm{C}$, por 48 horas. Cada diluição foi realizada em duplicata. A leitura foi realizada com o auxílio de um contador de colônias. Calculou-se o número de unidades formadoras de colônias (UFC) o qual foi expresso em UFC/g (Brasil, 2003).

\section{Contagem de bolores e leveduras}

Alíquotas de $1 \mathrm{~mL}$ das diluições preparadas conforme "Preparo das Amostras para Análise Microbiológica" foram transferidas para placas devidamente esterilizadas e adicionado $20 \mathrm{~mL}$ de Ágar Batata Dextrose (Acumedia, Lansing, Michigan, Estados Unidos), pH 3,5 acidificado com ácido tartárico $10 \%$. As placas foram incubadas a $25^{\circ} \mathrm{C}$. Após 5 dias realizouse a contagem de unidades formadoras de colônias (UFC), expressa em UFC/g (Brasil, 2003). Cada diluição foi realizada em duplicata.

\section{Contagem de Staphylococcus coagulase positiva}

Para a quantificação de Staphylococcus coagulase positiva foi utilizado o método de contagem "Spreadplate" em Ágar Baird Parker (BP), em duplicata depositando-se $0,1 \mathrm{~mL}$ de cada diluição $\left(10^{-3}, 10^{-4}, 10^{-}\right.$ $\left.{ }^{5}\right)$ sobre a superfície do ágar e, com auxílio da alça de Drigalsky. Após, o inócuo foi espalhado na superfície do meio até a completa absorção. As placas foram incubadas invertidas, em estufa, a $37^{\circ} \mathrm{C}$, por 24 a 48 horas (APHA, 1992). Foram selecionadas para contagem placas que continham número de colônias entre 20 e 200. Colônias características de Staphylococcus foram submetidas às provas bioquímicas de catalase e coloração de Gram. Também foram selecionadas três colônias típicas de cada placa as quais foram inoculadas em tubos contendo Caldo Infusão Cérebro Coração (BHI), os quais foram incubados a $37^{\circ} \mathrm{C}$, por 24 horas. A partir do subcultivo crescido em BHI, realizou-se a prova bioquímica confirmativa de coagulase em tubo.

\section{Pesquisa de Salmonella spp.}

Alíquotas de $25 \mathrm{~g}$ de cada amostra foram transferidas, assepticamente, para frascos contendo $225 \mathrm{~mL}$ de água peptonada tamponada para realização do pré-enriquecimento. Os frascos foram incubados por 24 horas, em estufa a $37^{\circ} \mathrm{C}$. Alíquotas de $1,0 \mathrm{~mL}$ e $0,1 \mathrm{~mL}$ do enriquecimento não seletivo foram inoculadas, respectivamente, em $10 \mathrm{~mL}$ de caldo Selenito-Cistina (SC) (HiMedia, Mumbai, Índia) e em $10 \mathrm{~mL}$ de caldo Rappaport-Vassiliadis (RV) (HiMedia). O caldo SC foi incubado a $37^{\circ} \mathrm{C}$, por $24 \mathrm{~h}$ e o caldo $\mathrm{RV}$ a $42^{\circ} \mathrm{C}$ por 24 h. Ágar Hektoen entérico Hektoen (Acumedia) e Ágar Xilose Lisina Desoxicolato de Sódio (XLD) (Acumedia) foram utilizados como meios sólidos seletivos e diferenciais e incubados a $37^{\circ} \mathrm{C}$, por $24 \mathrm{~h}$. Colônias características de Salmonella foram submetidas à triagem bioquímica utilizando-se: Prova Agar Tríplice Açúcar Ferro (TSI), Prova do Citrato de Simmons, Prova do Vermelho de Metila (VM), Prova do Voges-Proskauer (VP), Prova de descarboxilação da Lisina, Prova de $\mathrm{H}_{2} \mathrm{~S}$, indol e motilidade (Koneman et al., 2006).

\section{RESULTADOS E DISCUSSÃO}

Dentre as amostras de salame $(n=12)$, quatro possuíam selo do Serviço de Inspeção Estadual (S.I.P), sete possuíam selo do Serviço de Inspeção Municipal e uma não possuía qualquer tipo de selo de inspeção. Dentre as amostras de queijo $(n=10)$, três possuíam selo do Serviço de Inspeção Estadual (S.I.P), três possuíam selo do Serviço de Inspeção Municipal e quatro não possuía qualquer tipo de selo de inspeção (Tabela 1). Para atendimento a legislação vigente todos os alimentos devem ser inspecionados, por órgão governamental, em todas as fases. Em nível federal, as normas que regulam a inspeção industrial e sanitária 
Tabela 1 - Número mais provável (NMP/g) de coliformes totais e coliformes termotolerantes em amostras de salames e queijos coloniais produzidos e comercializados na Região Sudoeste do Paraná

\begin{tabular}{cccc}
\hline Amostras & Coliformes totais $(\mathrm{NMP} / \mathrm{g})$ & Coliformestermotolerantes (NMP/g) & \multicolumn{2}{c}{ Serviço de inspeção } \\
\hline S1 & 1.100 & 360 & S.I.P. \\
S2 & 360 & 0,0 & S.I.M. \\
S3 & 0,0 & 0,0 & S.I.P. \\
S4 & 300 & 0,0 & S.I.M. \\
S5 & 360 & 0,0 & S.I.M. \\
S6 & 360 & 0,0 & S.I.P. \\
S7 & $>1.100$ & $>1.100^{*}$ & Sem inspeção \\
S8 & 0,0 & 0,0 & S.I.P. \\
S9 & 0,0 & 0,0 & S.I.M. \\
S10 & 1.100 & $>1.100^{*}$ & S.I.M. \\
S11 & 0,0 & 0,0 & S.I.M. \\
S12 & $>1.100$ & 0,0 & S.I.M. \\
Q1 & $>1.100$ & 7,2 & S.I.P. \\
Q2 & $>1.100$ & $>1.100^{*}$ & S.I.P. \\
Q3 & $>1.100$ & $>1.100^{*}$ & S.I.P. \\
Q4 & $>1.100$ & $>1.100^{*}$ & S.I.M. \\
Q5 & 210 & $>1.100^{*}$ & S.I.M. \\
Q6 & 240 & 3,0 & S.I.M. \\
Q7 & 7,2 & 29 & Sem inspeção \\
Q8 & $>1.100$ & 7,2 & Sem inspeção \\
Q9 & $>1.100$ & $>1.100^{*}$ & Sem inspeção \\
Q10 & S.10 & Sem inspeção \\
\hline
\end{tabular}

Correto: S = salame; Q = queijos; S.I.P. = Serviço de Inspeção Estadual; S.I.M.= Serviço de Inspeção Municipal.

* Imprópria para consumo humano.

de produtos de origem animal estão descritas no Regulamento de Inspeção Industrial e Sanitária de Produtos de Origem Animal - RIISPOA (Brasil, 1980).

Dentre as amostras de salame $(\mathrm{n}=12)$ e queijo colonial $(\mathrm{n}=10), 18$ amostras $(81,8 \%)$ apresentaram contagens de coliformes totais entre 7,2 NMP/g a > 1.100 NMP/ g e 11 amostras (50\%) apresentaram contagem de coliformes totais $>1.100 \mathrm{NMP} / \mathrm{g}$, sendo quatro amostras de salame e sete de queijo (Tabela 1). Lobo et al. (2001) ao analisarem 60 amostras de salames coloniais comercializados em Santa Maria (RS), observaram que a grande maioria das amostras apresentava-se com alto grau de contaminação com bactérias do grupo coliformes totais. A legislação sanitária vigente não exige a análise desse grupo de bactérias em amostras de salame e de queijo (Brasil, 2001), porém, são, em geral, contaminantes ambientais, altas contagens são indicativas da ocorrência de inadequações higiênicas durante o processamento do produto.

Dentre as amostras de salame, três (25\%) apresentaram contaminação com bactérias do grupo coliformes termotolerantes, sendo que duas amostras apresentaram contagens superiores a 1100 NMP/g (Tabela 1). As amostras de queijos analisadas apresentaram contagens de coliformes termotolerantes entre 3,0 e $>1.100 \mathrm{NMP} / \mathrm{g}$ e $50 \%$ das amostras de queijo apresentaram contagem de coliformes termotolerantes $>1.100 \mathrm{NMP} / \mathrm{g}$ (Tabela 1). A Resolução RDC n ${ }^{\circ} 12$ estabelece os padrões microbiológicos para alimentos, a fim de garantir proteção à saúde da população. Para o salame, o máximo tolerado de coliformes termotolerantes/ $\mathrm{g}$ é de $10^{3} \mathrm{e}$ para queijos de média umidade o máximo tolerado de coliformes termotolerantes/g é de $10^{3}$ (Brasil, 2001).

Contatou-se, no entanto, que duas amostras de salame $(16,66 \%)$ estavam impróprias para o consumo sendo que uma das amostras apresentava registro de Serviço de Inspeção Municipal (SIM) e a outra não possuía nenhum registro de inspeção. Já em relação aos queijos $50 \%$ das amostras apresentaram-se impróprias para o consumo e dessas, duas apresentavam Serviço de Inspeção Municipal (SIM), duas pelo Serviço de Inspeção Estadual (SIP) e uma era de fabricação artesanal (sem inspeção). É importante ressaltar as contagens 
altas de coliformes termotolerantes em amostras industrializadas, que são fiscalizadas por órgãos oficiais e deveriam atender aos requisitos mínimos de elaboração dos produtos. Os salames e queijos que possuem SIM e SIP têm suas instalações inspecionadas por fiscais da Secretaria de Agricultura do Estado ou por fiscais do Ministério da Agricultura, Pecuária e Abastecimento (MAPA), e devem seguir os padrões de qualidade exigidos por esses órgãos, enquanto os queijos artesanais não são submetidos à inspeção.

Os resultados deste estudo são semelhantes aos observados por Viott et al. (2006). Esses autores avaliaram 12 amostras de salames coloniais na região do Alto Uruguai Catarinense-SC e constataram que $25 \%$ das amostras estavam em desacordo com o padrão com relação à contagem de coliformes termotolerantes. Lobo et al. (2001) constataram em 35\% dentre 60 amostras de salames coloniais comercializados em Santa Maria (RS), presença de coliformes termotolerantes acima do limite permitido pela legislação. Resultados superiores também foram encontrados por Ritter et al. (2003) ao analisarem 13 amostras de salames coloniais comercializados na região do Vale do Taquari (RS), verificaram que $54 \%$ das amostras com presença de coliformes termotolerantes. Giongo et al (2011) avaliaram 7 amostras de salame colonial na região sudoeste do Paraná e constataram que $71 \%$ das amostras possuía coliformes termotolerantes. Oliveira et al. (2014) ao analisarem 30 amostras de salame colonial de diferentes municípios do sudoeste paranaense verificaram que $10 \%$ de amostras apresentaram coliformes termotolerantes.

Quanto às amostras de queijos, os resultados da contagem de coliformes termotolerantes são semelhantes aos de Santos-Koelln et al. (2009) no qual 42,85\% das amostras analisadas apresentaram acima do limite estabelecido pela legislação. Salotti et al. (2006) observaram que $66,7 \%$ das amostras artesanais e $86,7 \%$ das amostras inspecionadas estavam em desacordo com a legislação em vigor. Contaminação maior por coliformes foi constatada em estudo desenvolvido por Ide \& Benedet (2001) no qual apenas duas das vinte e cinco amostras analisadas estavam em conformidade com os padrões e as demais encontravam acima e, portanto, inadequadas para o consumo. Oliveira et al. (2012) avaliaram 32 amostras de queijos coloniais e constataram que $50 \%$ encontravam-se acima dos padrões da legislação vigente.
A presença de coliformes termotolerantes é indicativa de contato direto e/ou indireto do produto alimentício com fezes, uma vez que $E$. coli não faz parte da microbiota normal de produtos frescos, por apresentar habitat exclusivo no intestino do homem e animais de sangue quente. Além de indicar a possível presença de enteropatógenos, várias cepas de E. coli são patogênicas ao homem (Franco \& Landgraf, 2008).

As médias obtidas na contagem de aeróbios mesófilos em amostras de salame colonial variaram de $8,7 \times 10^{5} \mathrm{UFC} / \mathrm{g}$ a 2,43 x $10^{8} \mathrm{UFC} / \mathrm{g}$ e as médias obtidas na contagem de mesófilos em amostras de queijo colonial variaram de $5,0 \times 10^{2} \mathrm{UFC} / \mathrm{g}$ a 2,25 x $10^{5} \mathrm{UFC} / \mathrm{g}$ (Tabela 2). Em estudo semelhante Hoffmann et al. (1997) analisaram oito (08) amostras de salame industrializados na região de São José do Rio Preto-SP, e a contagem de bactérias aeróbias mesófilas variou de $1,3 \times 10^{3}$ a 8,2 x $10^{8} \mathrm{UFC} /$ g. Alta contaminação por mesófilos também foram relatadas por Ritter et al. (2003) ao analisarem 13 amostras de salame coloniais comercializados na região do Vale

Tabela 2 - Contagem de mesófilos aeróbios (UFC/g) e de bolores e leveduras (UFC/g) em amostras de salames e queijos coloniais produzidos e comercializados na Região Sudoeste do Paraná

\begin{tabular}{|c|c|c|}
\hline Amostras & $\begin{array}{c}\text { Mesófilos } \\
\text { aeróbios (UFC/g) }\end{array}$ & $\begin{array}{c}\text { Bolores e } \\
\text { leveduras (UFC/g) }\end{array}$ \\
\hline $\mathrm{S} 1$ & $1,98 \times 10^{7}$ & $5,30 \times 10^{7}$ \\
\hline $\mathrm{S} 2$ & $1,30 \times 10^{8}$ & $6,10 \times 10^{6}$ \\
\hline $\mathrm{S} 3$ & $8,70 \times 10^{5}$ & $4,25 \times 10^{6}$ \\
\hline $\mathrm{S} 4$ & $6,80 \times 10^{6}$ & $3,65 \times 10^{6}$ \\
\hline S5 & $1,14 \times 10^{8}$ & $9,10 \times 10^{7}$ \\
\hline S6 & $3,45 \times 10^{6}$ & $9,15 \times 10^{7}$ \\
\hline S7 & $2,43 \times 10^{8}$ & $>1,50 \times 10^{8}$ \\
\hline S8 & $3,99 \times 10^{6}$ & $1,50 \times 10^{4}$ \\
\hline S9 & $4,00 \times 10^{6}$ & $7,00 \times 10^{5}$ \\
\hline S10 & $1,52 \times 10^{7}$ & $5,70 \times 10^{5}$ \\
\hline S11 & $2,70 \times 10^{7}$ & $5,50 \times 10^{5}$ \\
\hline S12 & $1,88 \times 10^{6}$ & $5,50 \times 10^{6}$ \\
\hline Q1 & $3,85 \times 10^{3}$ & $6,70 \times 10^{4}$ \\
\hline $\mathrm{Q}^{2}$ & $6,05 \times 10^{4}$ & $9,60 \times 10^{4}$ \\
\hline Q3 & $2,50 \times 10^{3}$ & $4,25 \times 10^{4}$ \\
\hline $\mathrm{Q}^{4}$ & $9,25 \times 10^{4}$ & $1,31 \times 10^{5}$ \\
\hline Q5 & $6,15 \times 10^{4}$ & $3,00 \times 10^{5}$ \\
\hline Q6 & $5,60 \times 10^{4}$ & $3,00 \times 10^{5}$ \\
\hline Q7 & $5,00 \times 10^{2}$ & $7,45 \times 10^{4}$ \\
\hline Q8 & $3,95 \times 10^{3}$ & $3,50 \times 10^{4}$ \\
\hline Q9 & $2,25 \times 10^{5}$ & $1,89 \times 10^{4}$ \\
\hline CQO & $5,65 \times 10^{4}$ & $2,45 \times 10^{5}$ \\
\hline
\end{tabular}

$\mathrm{S}=$ salame; $\mathrm{Q}=$ queijo. 
do Taquari-RS, os resultados variaram entre $10^{7}$ e $10^{8}$ UFC/g. Resultados superiores para a contagem de mesófilos foram obtidas por Roos et al. (2005) ao avaliaram queijo colonial obtido em feiras livres na cidade de Três Passos, RS e cujas contagens variaram de $1,5 \times 10^{7}$ a $2,5 \times 10^{10} \mathrm{UFC} / g$. Isepon et al. (2003) observaram contagens de $1,9 \times 10^{6}$ a $6,5 \times 10^{7} \mathrm{UFC} /$ g e Hoffmann at al. (1997) obtiveram contagens de 4,8 x $10^{7}$ a $2,8 \times 10^{12} \mathrm{UFC} / \mathrm{g}$.

A legislação brasileira não apresenta valores mínimos ou máximos de contagem de mesófilos em salames e queijos, mas altas quantidades de mesófilos em alimentos podem indicar que os mesmos foram preparados com matéria-prima altamente contaminada, que o processo foi insatisfatório do ponto de vista sanitário ou que os alimentos foram estocados em condições inadequadas de tempo e temperatura (Leite Junior et al., 2000; Roos et al., 2005).

A contagem de fungos filamentosos e leveduras em amostras de salame colonial variaram de $1,5 \times 10^{4}$ UFC/g a > 1,5 x $10^{8} \mathrm{UFC/g}$ e em queijo colonial a contagem variou de $1,89 \times 10^{4} \mathrm{UFC} / \mathrm{g}$ a $3,00 \times 10^{5} \mathrm{UFC} /$ g (Tabela 2).

Em estudos realizados por Dalla Santa(2008) ao analisar 50 amostras de salames coloniais fabricados por pequenas indústrias da região Sul do Brasil, observouse que algumas das amostras de salames apresentaram contagens de bolores e leveduras inferiores a $2 \log$ UFC/g. Entretanto, algumas das amostras apresentaram contagem acima de $6 \log \mathrm{UFC} / \mathrm{g}$. Em todas as amostras verificou a predominância do crescimento de leveduras em relação aos bolores, estes últimos multiplicam-se, principalmente, na superfície dos salames. Ritter et al. (2003) também constataram altas contagens de bolores e leveduras em salame coloniais comercializados na região do Vale do Taquari com contagens iniciais de $10^{5}$ UFC/g, enquanto que as contagens após 45 dias apresentaram redução de apenas 1 log, ou seja, média de $10^{4} \mathrm{UFC} / \mathrm{g}$. Ao analisar amostras de queijo coalho, Feitosa (1984) observou resultados semelhantes com relatos de contagens de bolores e leveduras entre 8,6 x $10^{3}$ a 3,2 x $10^{6} \mathrm{UFC} / \mathrm{g}$.

Apesar de não haver limites estabelecidos na legislação brasileira para bolores e leveduras em produtos curados e maturados, a presença desses microorganismos é um indicador de qualidade dos produtos alimentícios. Segundo Ritter et al.(2003) os fungos representam um perigo a saúde dos consumidores de salames coloniais considerando a possibilidade de produzirem micotoxinas extremamente perigosas ao homem, como aflatoxinas.

Dentre as amostras de salame colonial, 16,6\% apresentaram resultado positivo para Escherichia coli e das dez amostras de queijo analisadas, $40 \%$ apresentaram resultado positivo para $E$. coli (Tabela 3 ).

A legislação brasileira não estabelece padrões específicos para E. coli (Brasil, 2001), porém a presença desse micro-organismo em alimento, além de ser um indicador de contaminação fecal, também representa riscos à saúde dos consumidores, pois diversas linhagens de E. coli são comprovadamente patogênicas para o homem e para os animais (Franco \& Landgraf, 2008). Na literatura são revelados vários casos da presença de E. coli O157:H7 em salames fermentados (Incze, 1998; Siriken et al., 2006; Pereira, 2008). Os resultados do presente estudo vão ao encontro daqueles obtidos por Hoffmann et al. (1997) que ao analisarem oito (08)

Tabela 3 - Análise da presença e ausência de Escherichia coli e Salmonella spp. em amostras de salames e queijos coloniais produzidos e comercializados na Região Sudoeste do Paraná

\begin{tabular}{|c|c|c|}
\hline Amostras & $\begin{array}{c}\text { Escherichia coli } \\
\text { Presença/ausência }\end{array}$ & $\begin{array}{l}\text { Salmonella spp } \\
\text { Presença/ausência }\end{array}$ \\
\hline $\mathrm{S} 1$ & Ausência & Ausência \\
\hline $\mathrm{S} 2$ & Ausência & Ausência \\
\hline S3 & Ausência & Ausência \\
\hline $\mathrm{S} 4$ & Ausência & Ausência \\
\hline $\mathrm{S} 5$ & Ausência & Ausência \\
\hline S6 & Ausência & Ausência \\
\hline S7 & Presença & Ausência \\
\hline S8 & Ausência & Ausência \\
\hline S9 & Ausência & Ausência \\
\hline $\mathrm{S} 10$ & Presença & Ausência \\
\hline $\mathrm{S} 11$ & Ausência & Ausência \\
\hline $\mathrm{S} 12$ & Ausência & Ausência \\
\hline Q1 & Ausência & Ausência \\
\hline $\mathrm{Q}^{2}$ & Ausência & Ausência \\
\hline Q3 & Ausência & Ausência \\
\hline $\mathrm{Q}^{4}$ & Ausência & Ausência \\
\hline Q5 & Presença & Ausência \\
\hline Q6 & Presença & Ausência \\
\hline Q7 & Ausência & Ausência \\
\hline Q8 & Presença & Ausência \\
\hline Q9 & Ausência & Ausência \\
\hline Q10 & Presença & Presença \\
\hline
\end{tabular}

$\mathrm{S}=$ salame; $\mathrm{Q}=$ queijo. 
amostras de salames industrializados na região de São José do Rio Preto-SP confirmaram a presença de $E$. coli em duas amostras.

Magnani et al. (2000) aos avaliarem 50 amostras de salames coloniais comercializados em Chapecó-SC encontraram resultados mais abusivos. Do total de amostras avaliadas $72 \%$ confirmaram a presença de E. coli. Viott et al. (2006) ao analisarem 12 amostras de salames coloniais na região do Alto Uruguai Catarinense-SC, observaram que 83,3\% apresentavamse contaminadas com E. coli.

Em relação às amostras de queijo submetidas à análise de $E$. coli resultados semelhantes foram observados em estudo realizado por Feitosa et al. (2003), que obtiveram $36,4 \%$ das amostras com confirmação para $E$. coli ao analisar queijos coalho. A contagem de $E$. coli é utilizada como indicador de contaminação fecal recente ou de condições higiênico-sanitárias insatisfatórias de processamento de alimentos (Feng et al., 2010).

Todas as amostras de salame analisadas neste estudo apresentaram ausência de Salmonella spp. em $25 \mathrm{~g}$ de salame colonial e 10\% das amostras de queijo apresentaram presença de Salmonella spp. em $25 \mathrm{~g}$ de queijo colonial (Tabela 3). Para salame, resultados semelhantes foram encontrados por Viott et al. (2006) ao analisarem 12 amostras de salames coloniais na região do Alto Uruguai Catarinense-SC, onde 100\% das amostras apresentaram ausência para Salmonella spp. Em contrapartida, em estudo realizado por Magnani et al. (2000) analisando 50 amostras de salames coloniais comercializados em Chapecó-SC, esse patógeno foi detectado em $6 \%$ das amostras analisadas. Giongo et al. (2011) analisaram 7 amostras de salame do tipo colonial, 18 amostras do tipo italiano e 12 do tipo salamito, de diferentes frigoríficos da região Sudoeste do Paraná e verificaram a presença de Salmonella em $28 \%$ dos salames tipo colonial e em $5,5 \%$ dos salames tipo italiano. Oliveira et al. (2015) ao analisarem 30 amostras de salame colonial de diferentes municípios do sudoeste paranaense constataram que 16,6 apresentavam Salmonella sp.

Em relação aos queijos, estudos realizados por Antonello et al. (2012) e Oliveira et al. (2012) obtiveram $17,85 \%$ e $12,5 \%$ das amostras com resultados positivos para Salmonella, respectivamente.

Dentre as amostras de salame colonial, 50\% estavam contaminadas por Staphylococcus spp. e as contagens variaram de $4,0 \times 10^{4}$ a $2,0 \times 10^{6} \mathrm{UFC} / \mathrm{g}$. Do total de amostras contaminadas com Staphylococcus spp. uma apresentou resultado positivo no teste de coagulase (Tabela 4).

A legislação brasileira não estabelece padrões para Staphylococcus spp. em salame, entretanto, o máximo tolerado de Staphylococcus coagulase positiva é 5 x $10^{3} \mathrm{UFC} / \mathrm{g}$. Resultados diferentes foram observados por Hoffmann et al. (1997) ao analisaram 8 amostras de salame industrializados na região de São José do Rio Preto-SP, verificando-se presença de Staphylococcus aureus acima do permitido pela legislação em $75 \%$ das amostras analisadas. Já Lobo et al. (2001) ao analisarem 60 amostras de salames coloniais comercializados em Santa Maria-RS verificaram que do total de amostras avaliadas, $65 \%$ apresentavam $S$. aureus em contagens maiores que $10^{6} \mathrm{UFC} / \mathrm{g}$, valor considerado suficiente para a produção de toxina estafilocócica.

Já Klein et al. (2011) ao analisarem 18 amostras de salames coloniais comercializados em Concórdia-SC verificaram presença de Staphylococcus spp. coagulase positiva acima do permitido em $50 \%$ das amostras. Tussi et al. (2008) analisaram 20 amostras de salame colonial fabricado por 4 produtores do município de São Jorge D'oeste-PR e verificaram que $100 \%$ apresentaram contagem para $S$. aureus coagulase positiva.

A presença de $S$. aureus indica a ocorrência de contaminação veiculada por manipuladores, além de

Tabela 4 - Contagem de Staphylococcus ssp. (UFC/ g) coagulase positiva e negativa em amostras de salames coloniais produzidos e comercializados na Região Sudoeste do Paraná

\begin{tabular}{ccc}
\hline Amostras & $\begin{array}{r}\text { Staphylococcus } \\
\text { spp. }(\mathrm{UFC} / \mathrm{g})\end{array}$ & $\begin{array}{c}\text { Análise de } \\
\text { coagulase }\end{array}$ \\
\hline S1 & 0 & Negativo \\
S2 & 0 & Negativo \\
S3 & 0 & Negativo \\
S4 & 0 & Negativo \\
S5 & 0 & Negativo \\
S6 & $4,0 \times 10^{4}$ & Negativo \\
S7 & $3,8 \times 10^{5}$ & Negativo \\
S8 & 0 & Negativo \\
S9 & $2,0 \times 10^{6}$ & Pesitivo \\
S10 & $1,0 \times 10^{5}$ & Negativo \\
S11 & $3,0 \times 10^{5}$ & Negativo \\
S12 & $2,0 \times 10^{6}$ & \\
\hline
\end{tabular}


higiene inadequada das superfícies e utensílios, materiais e equipamentos, pois o principal reservatório de estafilococos na natureza é o homem e os animais, bem como solo e ar. Esse microrganismo pode ser transferido para o alimento durante ou após o processamento, por meio da manipulação inadequada e refrigeração insuficiente, o que pode ocasionar o seu crescimento e a produção e liberação de enterotoxinas nos alimentos (Lancette \& Bennett, 2001).

\section{CONCLUSÕES}

As amostras de salame apresentaram qualidade microbiológica adequada em relação a Salmonella spp. A contagem de coliformes totais, coliformes termotolerantes, presença de Eschericia coli e Staphylococcus coagulase positiva podem ser um indício de condições higiênico-sanitárias inadequadas durante o processamento, transporte e distribuição dos salames, considerando-se que $E$. coli na maioria das vezes é transmitida pela água ou por equipamentos e utensílios e o principal transmissor do $S$. aureus é o homem.

A maioria das amostras de queijo encontra-se em descordo com a legislação brasileira em vigor, pois apresentaram elevadas contagens de coliformes totais e metade das amostras não atende à legislação vigente quanto à presença de coliformes termotolerantes. Verificou-se também amostras contaminadas com $E$. coli e com Salmonella spp. tornando os queijos impróprios para o consumo humano.

Diante desses resultados concluiu-se que o consumo de salame e de queijo colonial constitui motivo de preocupação para as autoridades sanitárias regionais por representar um risco à saúde dos consumidores devido à presença de bactérias patogênicas como Salmonella sp., S. aureus e E. coli, capazes de causar enfermidade grave ao homem. A presença desses patógenos e a grande incidência de coliformes totais, coliformes termotolerantes, mesófilos aeróbios, bolores e leveduras nas amostras analisadas podem ser indicativos da baixa qualidade higiênico-sanitária do produto devido a procedimentos higiênicos inadequados durante a fabricação, manutenção em temperatura inadequada e ao uso de matéria prima de baixa qualidade higiênica, como leite não pasteurizado.

Ressalta-se a importância de uma fiscalização mais rigorosa e efetiva, assim como, a adoção de medidas higiênico-sanitárias adequadas, a implantação de Boas
Práticas de Fabricação, bem como cursos de atualização aos produtores.

\section{LITERATURA CITADA}

ANTONELLO, L; KUPKOVSKI, A.; BRAVO, C.C. Qualidade microbiológica de queijos coloniais comercializados em Francisco Beltrão, Paraná.

Revista Thema, v.9, n.1, p.1-6, 2012.

BRASIL. Ministério da Agricultura e do Abastecimento. Instrução Normativa no 22 de 31 de junho de 2000, Anexo V. Regulamento Técnico de Identidade e Qualidade de Salame. Diário Oficial [da] República Federativa do Brasil, Brasília, 3 ago. 2000.

BRASIL. Ministério da Agricultura, Pecuária e Abastecimento. Instrução Normativa n ${ }^{\circ} 62$ de 26 de agosto de 2003. Oficializa os métodos analíticos oficiais para análises microbiológicas para controle de produtos de origem animal e água. Diário Oficial [da] República Federativa do Brasil, Brasília, 18 set. 2003. p.14.

BRASIL. Ministério da Agricultura. R.I.I.S.P.O.A. 1980. Regulamento da Inspeção Industrial e Sanitária de Produtos de Origem Animal (Aprovado pelo decreto n. 30690, de 20.03.52, alterado pelo decreto n. 1255 , de 25.06.52). Brasília. 66p.

BRASIL. Ministério da Saúde. Agência Nacional de Vigilância Sanitária. Resolução n. 12, de 2 janeiro de 2001. Regulamento técnico sobre padrões microbiológicos para alimentos. Diário Oficial [da] República Federativa do Brasil, Brasília, 10 jan. 2001, n. 7-E, Seção 1 .

CAVALCANTE, J.F.M.; ANDRADE, N.J.; FURTADO, M.M. et al. Processamento do queijo coalho regional empregando leite pasteurizado e cultura lática endógena. Ciência e Tecnologia dos Alimentos, v.27, n.1, p. 205-214, 2007.

DAlla SANTA, R.O. Avaliação da qualidade de salames artesanais e seleção de culturas starter para a produção de salame tipo italiano. Tese (Mestrado em Tecnologia de Alimentos). Curitiba, PR:UFPR, 2008. 133p. 
FARIÑA, L.O.; KURUMIYA, R.; TAKANO, D. et al. Análise de composição e avaliação da acidez do Queijo Colonial produzido por agricultores familiares de Céu Azul (PR). In: CONGRESSO DE CIÊNCIAS FARMACÊUTICAS, 3, E SIMPÓSIO EM CIÊNCIAETECNOLOGIADEALIMENTOS DO MERCOSUL, 3, 2008, Anais... Cascavel, 2008.

FEITOSA, T. Estudos tecnológicos, físicoquímicos, microbiológicos e sensoriais do queijo de coalho do estado do Ceará. Dissertação (Mestrado em Tecnologia de Alimentos). Fortaleza, Ce:UFC, 1984.91p.

FEITOSA, T; BORGES, M.F.; NASSU, R.T. et al. Pesquisa de Salmonella sp., Listeria sp. e microrganismos indicadores higiênico-sanitários em queijos produzidos no Estado do Rio Grande do Norte. Ciência e Tecnologia dos Alimentos, v.23, Suppl.10, p.162-165, 2003..

FENG; P.; WEAGANT, S. D.; GRANT, M.A. Enumeration of Escherichia coli and the coliform bacteria. Bacteriologycal Analytical Manual Online, v.4, p.1-14, 2002. In: http:// www.cfsan.fda.gov/ ebam/bam-4.html (acessado em 17 de abril de 2017).

FRANCO, B.D.G.M.; LANDGRAF, M. Microbiologia dos alimentos. São Paulo: Atheneu, 2008. 182p.

FREO, J.D.; REOLON, J.I. Qualidade dos produtos derivados de carne e leite, industrializados pelas agroindústrias de Frederico Westphalen, RS.

Higiene Alimentar, v.21, n.140, p.53-59, 2006.

GIONGO, C.N.; SCHIDLOWKI, L.; LARA, A.A. Qualidade microbiológica de salames tipo colonial, salamito e italiano produzidos na Região Sudoeste do Paraná. In: CONGRESSO DE CIÊNCIA E TECNOLOGIA DA UTFPR, 1., 2011. Anais... Dois Vizinhos: UTFPR, 2011.

GOTTARDO, E.T.; VIANA, C.; BARCELLOS, V.C. et al. Embutidos cárneos fermentados artesanais como veículos de micro-organismos patogênicos de importância para saúde pública. Boletim. CEPPA, v.29, n.1, p.97-102, 2011.

HOFFMANN, F.L.; GARCIA-CRUZ, C.H.; VINTURIM, T.M. Estudo higiênico-sanitário preliminar de amostras de salame. Higiene Alimentar, v.11, n.47, p.42-44, 1997.
HOLOWKA, H.; KIYOTA, N.; PAZ, C.R.S. Plano de Desenvolvimento Sustentável do Sudoeste do Paraná. In: FÓRUM INTERGOVERNAMENTALE DA SOCIEDADE DO SUDOESTE DO PARANÁ, 2, 1999, Anais... Francisco Beltrão, 2007.

IDE, L.P.A.; BENEDET, H.D. Contribuição ao conhecimento do queijo colonial produzido na região serrana do Estado de Santa Catarina, Brasil. Ciência e Agrotecnologia, v.25, n.6, p.1351-1358, 2001.

INCZE, K. Dry fermented sausages. Meat Science, v.49, suppl. 1, p.169-177, 1998.

ISEPON, J.S.; SANTOS, P.A.; SILVA, M.A.P. Avaliação microbiológica de queijos minas frescal comercializado na cidade de Ilha Solteira-SP.

Higiene Alimentar, v.17, n.106, p.89-94, 2003.

KLEIN, C.S.; ZOTTI, T.R.; GAVA, A. et al. Qualidade microbiológica de salames tipo colonial comercializados na cidade de Concórdia-SC: análise de Staphylococcus aureus e Toxoplasma gondii. Concórdia, SC:.Embrapa Suínos e Aves. In: Comunicado Técnico, 446, 2006.

KONEMAN, E.W; ALLEN, S.D.; JANDA, W.M. et al. Diagnóstico Microbiológico. São Paulo: MEDSI, 2006. 1464p.

KOTTWITZ, L.B.M.; GUIMARÃES, I.M. Avaliação microbiológica de queijos coloniais produzidos no Estado do Paraná. Higiene Alimentar, v.17, p.77-80, 2003.

LANCETTE, G.A.; BENNETT, R.W. Staphylococcus aureus and Staphylococcal Enterotoins. In: DOWNES, F.P.; ITO, K. Compendium of methods for the microbiological examinations of foods. 4.ed. Washington: American Public Health Association - APHA, Cap. 39, p.387-403, 2001. 676p.

LEITE JUNIOR, A.F.S; FLORENTINO, E.R.; OLIVEIRA, E.B. et al. Qualidade microbiológica do queijo tipo coalho comercializado à temperatura ambiente ou sob refrigeração, Campina Grande, PB. Higiene Alimentar, v.14, n.73, p.53-59, 2000.

LINDQVIST, R.; LINDBLAB, M. Inactivation of Escherichia coli, Listeria monocytogenes and Yersinia enterocolitica in fermented sausages during maturation/storage. International Journal of Food Microbiology, v.129, n.1, p.59-67, 2009. 
LOBO, M.V.; UGALDE, M.G.; FRIES, L.L.M. et al. Avaliação microbiológica de salames coloniais comercializados no município de Santa Maria-RS. Higiene Alimentar, v.15, n.88, p.57-61, 2001.

MAGNANI, A.L.; GIOMBELLI, A.; SCHUCK, M.S. et al. Incidência de Salmonella e Escherichia coli em carne suína in natura e salame colonial consumidos pela população de Chapecó-SC. Higiene Alimentar, v.14, n.73, p.44-47, 2000.

MAGRO, G.R.; KLEIN, C.S. Qualidade microbiológica de salames tipo colonial comercializados na cidade de Concórdia-SC: análise de Salmonella, coliformes totais e termotolerantes. Concórdia, SC: Embrapa Suínos e Aves. In:

Comunicado Técnico, 449, 2006.

MARCHI, J.F.; LAVORATI, N.; SOARES, J.A.Z. et al. Desenvolvimento sócio-econômico das agroindústrias familiares do Sudoeste do Paraná. In: Seminário Sistemas de Produção Agropecuária da UTFPR, 1., 2007. Anais... Dois Vizinhos, 2007.

OLIVEIRA, D.F.; BRAGHINI, F.; SILVEIRA JÚNIOR, J.F.S. et al. Condições higiênico-sanitárias e composição nutricional de salames artesanais e industrializados: uma comparação. Arquivos de Ciência da Saúde da UNIPAR, v.18, n.3, p.151-156, 2014.

OLIVEIRA, D.F.; BRAVO, C.E.C.; TONIAL, I.B. et al. Sazonalidade como fator interferente na composição físico-química e avaliação microbiológica de queijos coloniais. Arquivo Brasileiro de Medicina Veterinária e Zootecnia, v.64, n.2, p.521-523, 2012.

OLIVEIRA, K.A.M.E.; MENDONÇA, R.C.S. Efeito da fermentação sobre a microbiota de embutidos cárneos. Higiene Alimentar, v.18, n.123, p.12-17, 2004.

PEREIRA, K.S. Patógenos bacterianos em salames. Revista Nacional da Carne, v.328, p.23-24, 2004.

RITTER, R.; SANTOS, D.; AGOSTINI, F.S. et al. Microbiologia contaminante e patogênica de linguiça (salame) colonial, analisada em quatro períodos distintos. Higiene Alimentar, v.17, n.113, p.60-66, 2003.
ROOS, T.B.; SCHEID FILHO, V.B.; TIMM, C.D. et al. Avaliação microbiológica de queijos coloniais produzidos na cidade de Três Passos. Higiene Alimentar, v.19, n.132, p. 94-96, 2005.

SALOTTI, B.M.; CARVALHO, A.C.F.B.; AMARAL, L.A. et al. Qualidade microbiológica do queijo minas frescal comercializado no município de Jaboticabal, SP, Brasil. Arquivos do Instituto Biológico, v.73, n.2, p.171-175, 2006.

SANTOS-KOELLN, F.T.; MATTANA, A.; HERMES, E. Avaliação microbiológica do queijo tipo mussarela e queijo colonial comercializado na região oeste do Paraná. Revista Brasileira de Tecnologia Agroindustrial, v.3, n.2, p.66-74, 2009.

SILVA, N.; JUNQUEIRA, V.C.A.; SILVEIRA, N.F.A. et al. Manual de métodos de análise microbiológica de alimentos e água. $4^{\mathrm{a}}$ Ed., São Paulo: Varela. 2010. 624p.

SIRIKEN, B.; PAMUK, S.; ÖZAKIN, C. et al. A note on the incidence of Salmonella spp., Listeria spp. and Escherichia coli O157:H7 serotypes in turkish sausage (Soudjouck). Meat Science, v.72, n.1, p.177-18, 2006.

TUSSI, E.K.; LOCATELLI, P.P.; ALFARO, A.T. et al. Avaliação da qualidade físico-química e microbiológica do salame colonial comercializado em São Jorge D' Oeste-PR. Synergismus scyentifica UTFPR, v.3, n.4, 2008.

TYÖPPÖNEN, S.; PETÄJ Ä, E.; MATTILASANDHOLM, T. Bioprotectives and probiotics for dry sausages. International Journal of Food Microbiology, v.83, n.3, p.233-244, 2003.

VIOTT, A.; STOLBERG, J.; PELISSER, M.R. Qualidade microbiológica e físico-química de salames tipo coloniais da região do Alto Uruguai Catarinense. Higiene Alimentar, v.20, n.138, p.78-83, 2006.

Recebido para publicação em 30/3/2017 e aprovado em 29/5/2017. 